\title{
POSTOPERATIVE ANALGESIA;
}

\section{Comparison of caudal bupivacine and bupivacaine - tramadol in children with inguinal hernia repair.}

\section{Dr. Asma Samee, Dr. M. Shafique Tahir, Dr. Nadeem Ahmad Khan, Dr. Muhammad Masood, Dr. Muhammad Yousaf, Dr. Salman Waris}

ABSTRACT... Objective: To compare the effects after caudal bupivacaine alone and bupivacaine-tramadol in young children with inguinal hernia repair. Setting: Department of Paediatric Anaesthesia, Children Hospital Complex, Multan. Period: August 2008 to May 2009. Material and methods: A total of 100 children aged between 2-5 years were included in the study. Results: The duration of analgesia was significantly prolonged in group-A patients $(P=0.001)$. A low frequency of postoperative vomiting was observed in both groups i.e. $10 \%$ in group- $A$ and $6.7 \%$ in group-B $(P=0.64)$. No respiratory depression, flushing and pruritis were observed. Conclusions: Low dose combination of bypivacaine and tramadol, when administered caudally, had an additive effect and provided prolonged and effective postoperative analgesia with minimal side effects.

Key words: Bupivacaine, Inguinal hernia, Tramadal.

\section{Article Citation}

$\checkmark \quad$ Samee A, Tahir MS, Khan NA, Masood M, Yousaf M, Waris S. Comparison of caudal bupivacine and bupivacaine - tramadol for postoperative analgesia in children with inguinal hernia repair. Professional Med J Feb 2013;20(1):095-098.

\section{INTRODUCTION}

Caudal block is the most common regional anaesthetic technique performed in children'. It is very reliable, safe and has a low failure rate. It can be used in children with general anaesthesia for intra- and postoperative analgesia in all procedures below the umbilicus including herniotomy, orchidopexy and penile surgeries ${ }^{2}$.

Administration of a single agent for caudal block with a high dose may provide a satisfactory analgesia but may cause side effects i.e. hypertension, respiratory depression etc ${ }^{3}$. To overcome this problem, two agents with low dose may prove superior in achieving effects i.e. prolonged effect and minimal side effects. Ketamine, clonidine and various opioids have been combined with bupivacaine with varied degrees of success.

Tramadol is a synthetic analogue of codine that has an analgesic potency approximately equal to that of pethidine but without respiratory depressant effect ${ }^{4}$. It has been shown to be as effective as bupivacaine in providing postoperative analgesia when administered caudally in children ${ }^{5}$.
The aim of this study was to compare the combination of $0.125 \%(0.6 \mathrm{ml} / \mathrm{kg})$ bupivacaine and tramodal $(1$ $\mathrm{mg} / \mathrm{kg})$ with bupivacaine $0.25 \%(0.6 \mathrm{ml} / \mathrm{kg})$ administered caudally in young children with inguinal hernia repair for reduction in dose of both agents and extension of the duration of analgesia.

\section{MATERIAL AND METHODS}

This study was carried out in the Department of Paediatric Anaesthesia, Children Hospital Complex, Multan from August 2008 to May 2009. A total of 100 children aged between 2-5 years, divided into two groups were included in the study. The patients in group-A received $0.125 \%$ bupivacaine $0.6 \mathrm{ml} / \mathrm{kg}$ with tramadol $1 \mathrm{mg} / \mathrm{kg}$ body weight caudally. Group-B patients received bupivacaine $0.6 \mathrm{ml} . \mathrm{kg}$ body weight caudally. Anaesthesia was discontinued after completion of surgery. A modified Toddler preschool postoperative pain scale (TPPPS) is a behavioural pain scale used to assess pain in infants and pre-school children ${ }^{6}$.

\section{RESULTS}

During the study period, 100 boys were enrolled. 50 in each group. The demographic features i.e. age and weight of children in both groups are shown in Table-II. 


\begin{tabular}{|l|c|c|c|}
\hline Variable & Score-0 & Score-1 & Score-2 \\
\hline $\begin{array}{l}\text { Verbal } \\
\text { complaint/cry }\end{array}$ & None & 1 & $>1$ \\
\hline Groan/moan/grunt & None & 1 & $>1$ \\
\hline Facial expression & Neutral & 1 & Grimace $>1$ \\
\hline $\begin{array}{l}\text { Restless motor } \\
\text { behaviour }\end{array}$ & None & 1 & $>1$ \\
\hline $\begin{array}{l}\text { Rub/touch/painful } \\
\text { area }\end{array}$ & None & 1 & $>1$ \\
\hline
\end{tabular}

Table-I. Modified TPPS pain score

\begin{tabular}{|l|c|c|c|c|}
\hline Feature & $\begin{array}{c}\text { All } \\
\text { patients }\end{array}$ & Group-A & Group-B & P-value \\
\hline $\begin{array}{l}\text { Age } \\
\text { (months) }\end{array}$ & $\begin{array}{c}37.72 \\
\pm 11.67\end{array}$ & $\begin{array}{c}38.57 \\
\pm 12.762\end{array}$ & $\begin{array}{l}36.87 \\
\pm 10.61\end{array}$ & 0.577 \\
\hline $\begin{array}{l}\text { Weight } \\
\text { (Kg) }\end{array}$ & $\begin{array}{c}17.38 \\
\pm 2.38\end{array}$ & $\begin{array}{c}17.31 \\
\pm 2.62\end{array}$ & $\begin{array}{l}17.45 \\
\pm 2.15\end{array}$ & 0.831 \\
\hline
\end{tabular}

Table-II. Mean age and weight

The mean duration of analgesia in both groups was compared using modified TPPPS. It was $10.4+1.69$ hours in group-A and $7.93+1.52$ hours in group-B $(P=0.001)$.

Mean hourly pain scores were similar upto 5 hours in both groups, but the scores were higher in group-B from 6 -10 hours after surgery $(P=0.05)$. In group-A, $56.7 \%$ patients did not require rescue analgesia upto 12 hours postoperatively, while in group-B all patients required rescue analgesia within 12 hours. After 12 hours, oral paracetamole was given to all patients who were awake, by ward nurses as a protocol.

There were no significant differences between the groups in mean hourly respiratory rate. Emesis occurred in 3 patients in group-A and 2 patients in group-B with no statistically significant difference $(P=0.064)$. No pruritis and flushing were observed in both groups.

\section{DISCUSSION}

Ease of performance and reliability makes caudal block the most commonly perofrrmed block in children. Caudal administration of bupivacaine is a widespread regional anaesthetic technique for intraand postoperative analgesia during lower limb, anoperineal, penoscrotal and abdominal surgical procedures in children ${ }^{7}$.

Unintentional intravascular injection of bupivacaine during caudal block placement may cause life threatening cardiovascular and central nervous system complications ${ }^{8}$. There have been reports of death attributable to bupivacaine induced cardiotoxicity in adults after accidental I/V injection ${ }^{9}$. Even an epidural test dose containing epinephrine does not reliably produce hemodynamic responses in children during inhalation anaesthesia ${ }^{10}$.

To overcome this problem as well as to increase the duration of analgesia, combining local anaesthetic agents with other drugs as adrenaline, clonidine, ketamine or various opioids have met with varying degrees of success ${ }^{3,11}$.

In this study, caudal block was performed in 60 children, 13-53 months of age, to compare the effects of bupivacaine alone with a low dose combination of bupivacaine with tramadol for inguinal hernia repair. The incidence of failed block is $2.8 \%$ in a study done ${ }^{2}$.

The effectiveness of the block was $100 \%$ in both groups. In one study, the effectiveness of caudal bupivacaine $0.25 \%(0.6 \mathrm{ml} / \mathrm{kg})$ was $94 \%$ in patients undergoing sub-umbilical surgery ${ }^{13}$. As we used a volume of $1 \mathrm{ml} / \mathrm{kg}$ for penile surgery, this much of volume is sufficient to block all the sacral, lumbar and lower thoracic segments ${ }^{14}$ and the block regresses slowly.

The duration of analgesia was longer and statistically significant in group-A patients. In a comparative study, 
caudal bupivacaine $0.25 \%(.6 \mathrm{ml} / \mathrm{kg}(-1)$ with the addition of tramadol $1.5 \mathrm{mg} / \mathrm{kg}(-1)$ resulted in significantly longer postoperative analgesia duration of $13+2.2$ hours $^{15}$. The difference in their duration of analgesia as compared to the present study is due to the low concentration of both agents. The combination of bupivicaine and tramadol was chosen for caudal block because caudal bupivicaine provides analgesia in the immediate postoperative period, whereas caudal tramadol provides analgesia in the late postoperative period thereby increasing the total duration of analgesia (additive effect) ${ }^{6}$.

The mean duration of action of caudal bupivacaine in this study is longer than that found in previous studies $^{16}$. Differences in the operations performed, method of pain scoring, bupivacaine dose and volume and calculation of analgesia time probably account for this discrepancy.

The overall frequency of vomiting seen in this study is $8.3 \%$ in both groups, $10 \%$ in group-A and $6.7 \%$ in group- $B$. the reason is unclear and may depend more upon other factors, such as the selection of sedatives or anaesthetic agents, rather than upon the agents used in caudal block.

If by 12 hours additional analgesia had been required, it was assumed for the sake of comparison that the duration of analgesia was 12 hours, although it is possible that useful analgesia may have continued for longer time in group-A patients. However, logistic problems dictated that further observations were impracticable and after 12 hours observations were completed, there was a tendency for prophylactic paracetamol analgesia to be given by the ward nurses to any patient who was still awake. All patients were managed successfully with paracetamol alone after this time.

All patients were catheterized during surgery, so urinary retention was not seen in both groups. No flushing and pruritis were observed in any patient in either group. The reason could be the low dose or tramadol.

\section{CONCLUSIONS}

Low dose combination of $0.125 \%$ bupivacaine and tramadol $1 \mathrm{mg} / \mathrm{kg}$ body weight injected caudally for inguinal hernia repair in young children had an additive effect and provided effective postoperative analgesia with minimal side effects. The duration of postoperative analgesia was significantly prolonged as compared to $0.25 \%$ bupivacaine.

\section{Copyright@ 20 Sep, 2012.}

\section{REFERENCES}

1. Gill P, Kiani S, Victoria BA, Atcheson R. Pre-emptive analgesia with local anaesthetic for herniorrhaphy. Anaesth 2001;56:414-7.

2. DeBeer DA, Thomas ML. Caudal additives in children: solutions or problems. Br Anaesth 2003; 90; 497-8.

3. Bernard JD. 7th ed. Churchill Livingstone Co; 2010. Regional Anesthesia in Children. In: Miller Anesthesia; pp. 2532-34.

4. Zeidan A, Kassem R, Nahleh N, Maaliki H, El-Khatib M, Struvs MM et al. Intraarticular tramadol bupivacaine combination prolongs the duration of postoperative analgesia after outpatient arthroscopic knee surgery. Anaesth Analg 2008; 107(1): 292-9.

5. Choudhuri AH, Dharmani P, Kumarl N, Prakash A. Comparison of caudal epidural bupivacaine with bupivacaine plus tramadol and bupivacaine plus ketamine for postoperative analgesia in children. Anaesth Intensive Care 2008; 36(2): 174-9.

6. Prosser DP, Davis a, Booker PD, Murray A. Caudal tramadol for postoperative analgesia in paediatric inguinal hernia surgery. Br J Anaesth 1997; 79: 293-6.

7. Sajedi P, Yaraghi A, Zadeh MTD. Comparison of pre- vs. post-incisional caudal bupivacaine for postoperative analgesia in unilateral pediatric herniorrhaphy. Saudi J Anaesth 2011; 5(2): 157-61. 
8. $\quad$ Ong CK, Lirk, Seymour RA, Jenkins BJ. The efficacy of preemptive analgesia for acute postoperative pain management: a meta-analysis. Anaes Analg 2005; 100(3): 757-73.

9. Senel AC, Akyol A, dohman D, Solak M. Caudal bupivacaine tramadol combination for postoperative analgesia in pediatric herniorrhaphy. Acta Anaesth Scand 2001; 45(6): 786-9.

10. Ozcengiz D, Gunduz M, Ozbek H, Isik G. Comparison of caudal morphine and tramadol for postoperative pain control in children undergoing inguinal herniorrhaphy. Paediatr Anaesth 2001;11: 459-64.

11. Fischer S, Troidl H, MacLean AA, Koehler L, Paul A. Prospective double-blind randomised study of a new regimen of pre-emptive analgesia for inguinal hernia repair: Evaluation of postoperative pain course. Eur $\mathrm{J}$ Surg 2000;166:545-51.

12. Gundey M. A comparison of single dose caudal tr amadol, tramadol plus bupivacaine \& bupivacaine administration for post-operative analgesia in children. Pediatr Anaesth 2001; 11(3): 323-26.

13. Senel.AC. Caudal bupivacaine-tramadol combination for postoperative analgesia in pediatric herniorrhaphy. Acta Anaesth Scand 2001 ; 45(6) : 786-89.

14. Locatelli B, Ingelmo P, Sonzogi V. Randomized, double blind, phase-III, controlled trial comparing levobupivacaine $0.25 \%$, ropivacaine $0.25 \%$ and bupivacaine $0.25 \%$ by the caudal route in children. $\mathrm{Br}$ J Anaesth 2005; 94: 366-71.

15. Armitage EN. Regional anaesthesia in paediatrics. Clin Anaesthesiol 1985; 3: 553-8.

16. Hong JY, Han SW, Kim WO, Cho JS, Kil HK. A comparison of high volume/low concentration and low volume/high concentration ropivacaine in caudal analgesia for pediatric orchiopexy. Anesth Analg 2009;109:1073-8.

\section{AUTHOR(S):}

1. DR. ASTHMA SAMEE

Assistant Professor Anaesthesiology, Children Complex, Multan

2. DR. M. SHAFIQUE TAHIR

Assistant Professor

Department of Anaesthesiology,

Nishtar Medical College/Hospital, Multan

3. DR. NADEEM AHMAD KHAN

Senior Registrar

Department of Anaesthesiology,

Nishtar Medical College/Hospital, Multan.

4. Dr. Muhammad Masood

Consultant Anaesthetist

Department of Anaesthesiology,

Nishtar Medical College/Hospital, Multan.
5. Dr. Muhammad Yousaf

Associate Professor

Department of Anaesthesiology, Nishtar Medical College/Hospital, Multan.

6. Dr. Salman Waris

Professor

Department of Anaesthesiology, Nishtar Medical College/Hospital, Multan.

Correspondence Address:

Dr. Asthma Samee

Assistant Professor Anaesthesiology

Children Complex, Multan

$\begin{array}{rr}\text { Article received on: } & 13 / 06 / 2012 \\ \text { Accepted for Publication: } & 20 / 09 / 2012 \\ \text { Received after proof reading: } & 10 / 12 / 2012\end{array}$

\section{PREVIOUS RELATED STUDIES}

Manzoor Ahmed Afridi, Syed Inamullah Shah, Abdul Hamid Bhatti, Musharraf Imam. POSTOPERATIVE ANALGESIA; A COMPARISON OF SUBLINGUAL BUPRENORPHINEAND INTRAMUSCULAR MORPHINE FOR PAIN RELIEF AFTERABDOMINAL HYSTERECTOMY (Original) Prof Med Jour 11(2) 152-157 Apr, May, Jun, 2004. 